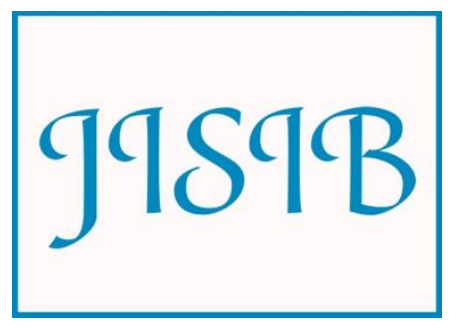

Available for free online at https://ojs.hh.se/

Journal of Intelligence Studies in Business Vol 4, No 2 (2014) 30-40

\title{
Integration of Business Intelligence and Knowledge Management - A literature review
}

\author{
Najibeh Abbasi Rostami ${ }^{1}$
}

${ }^{1}$ Isfahan University, Iran

Email: najibeh.abbasi@yahoo.com

Received September 27, accepted October 262014

\begin{abstract}
In today's world data are so numerous that technology is needed to cope with this knowledge. Business Intelligence (BI) is a process that involves sorting all the collected information and select those that are relevant. BI provides critical insights that help organizations make right decisions. Knowledge management (KM) is a key approach to solving current problems. KM can be defined as a systematic process of finding, selecting, organizing, distilling and presenting information in a way that improves an employee's comprehension in a specific area of interest. BI and $\mathrm{KM}$ play an important role in improving the qualitative and quantitative value of information available for decision making. KM and BI can also benefit from each other. It seems that integration of BI and KM can help organizations achieve wider benefits. Integration of BI and KM will not only help to promote and enhance knowledge for better decision making, but also improve an organization's performance. Therefore it is imperative for organizations to have both BI and $\mathrm{KM}$ as an integrated system to get full value from both. This paper is a literature review which shows the importance of BI and KM Integration through a series of models.
\end{abstract}

KEYWORDS: Business intelligence, knowledge management, integration, literature review 


\subsection{Introduction}

The environment in which firms operate is growing in complexity. Since the 1900's nearly three billion people have become players in the global stage, overcoming cultural, religious, ethnic, and political barriers to market entry. In addition to globalization, other environmental factors that are pressuring businesses to perform at high levels include: customer demand, government regulations, market conditions, and competition. To meet the performance challenge, companies require considerable volumes of timely, relevant, high quality data, information, and knowledge (Kimpel and Morris, 2013).

In most larger firms, there is a vast aggregation of documents and data, including business documents, forms, data bases, spreadsheets, e-mail, news and press articles, technical journals and reports, contracts, and web documents. Knowledge and content management applications and technologies are used to search, organize and extract value from these information sources and are the focus of significant research and development activities (Herschel and Jones, 2005). For example, the International Data Corporation (IDC) reported that digital data growth was up by 48 percent in 2012, with 90 percent of information being unstructured. As a result of this type of data complexity, many businesses are now challenged to understand and analyse the wide range of information involved. However, as many business users lack access to the information they need, many tend to make decisions based on instinctive knowledge that can result in loss of productivity, reduced agility in the marketplace, and flawed decision-making (Boonsiritomachai et al., 2014). Therefore business intelligence systems allow organizations to access, analyze, and share information and knowledge, which in turn helps to track, understand, target and manage their business in order to improve enterprise performance (Panian,2008).

In today's highly competitive and increasingly uncertain world, the quality and timeliness of an organization's "business intelligence" (BI) can mean not only the difference between profit and loss, but also even the difference between survival and bankruptcy (Ranjan, 2008). BI is a broad category of applications and technologies of gathering, accessing, and analyzing a large amount of data for the organization to make effective business decisions.

$\mathrm{BI}$ is primarily used to improve the timeliness and quality of information, and enable managers better understand the position of their firm as in comparison to competitors. BI applications and technologies help companies to analyze changing trends in market share; changes in customer behavior and spending patterns; customers' preferences; company capabilities; and market conditions. It is used to help analysts and managers determine which adjustments are most likely to respond to changing trends. It has emerged as a concept for analyzing collected data with the purpose to help decision making units get a better comprehensive knowledge of an organization's operations, and thereby make better business decisions (Khan \& Quadri, 2012).

In parallel with the development of paradigmatic knowledge economy, which emphasizes the role of knowledge in creating economic goods, grows the importance of knowledge management. Managing business information allows the use of remaining data, its collecting and converting into usable information. Managing the knowledge, through implementing various concepts, and using modern business intelligence tools, are necessary to gain a competitive advantage and survival in the markets.

Integrating Business Intelligence and Knowledge Management in new software applications designated not only to store highly structured data and exploit it in real time but also to interpret the results and communicate them to decision factors provides real technological support for Strategic Management. Integrating Business Intelligence and Knowledge Management in order to respond to the challenges the modern enterprise has to deal with represents not only a "new trend" in IT, but a necessity in the emerging knowledge based economy (Albescu et al., 2008).

With respect to the increasing importance of the use of BI and KM, and the importance Integrating Business Intelligence and Knowledge Management in knowledge based economy, it seems that integration $\mathrm{BI}$ and $\mathrm{KM}$ can be determined as one of the key success factors in modern business. Therefore, this article will address the importance of integration of BI and KM as key for successful organizations.

The article is structured as follows: section 2 provides definitions of BI and KM. In section 3, Similarities and distinction between BI and KM are presented. Section 4 discusses BI and KM benefits for the organization. Section 5 presents Integration of $\mathrm{KM}$ and $\mathrm{BI}$ with benefits, and the last section gives a brief summary of the article.

\subsection{Literature review}

\subsection{Defining Business Intelligence}

Understanding of business intelligence often differs by its content's focus as well as on several related terms used for referring to business intelligence (including competitive intelligence, competitor intelligence, strategic intelligence etc.) (Jaklic et al., 2009). 
Business intelligence is a natural outgrowth of a series of previous systems designed to support decision making. The emergence of the data warehouse as a repository, the advances in data cleansing that lead to a single truth, the greater capabilities of hardware and software, and the boom of Internet technologies that provided the prevalent user interface all combine to create a richer business intelligence environment than was available previously. BI pulls information from many other systems. Figure 1 depicts some of the information systems that are used by BI (Negash, 2004).

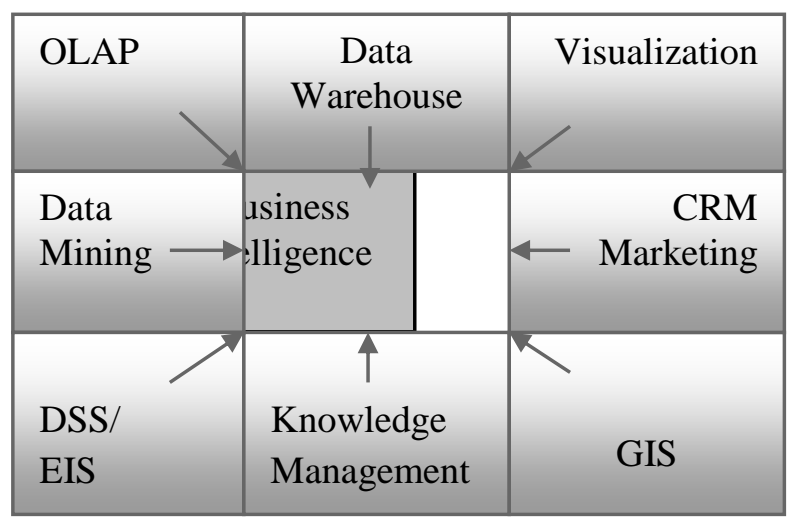

Figure 1: BI Relation to Other Information Systems. Where: OLAP = on-line data processing, CRM=customer relationship management, DSS= decision support systems, GIS = geographic information systems

BI is a set of business information and business analyses within the context of key business processes that lead to decisions and actions. In particular, BI means leveraging information assets within key business processes to achieve improved business performance (Williams \& Williams, 2007).

BI systems combine data gathering, data storage, and knowledge management with analytical tools to present complex internal and competitive information to planners and decision makers (AL-Shubiri, 2012). Business intelligence has been defined as solutions applying information technologies to retrieve heterogeneous and distributed resources in order to interpret, categorize, and integrate them, and then to formulate any potentially usable knowledge by employing analysis mechanisms (Vine, 2000). BI is the way and method of improving business performance by providing powerful assistance to executive decision maker which enables them to have actionable information at hand. BI tools are viewed as technology that enhances the efficiency of business operation by providing an increased value to the enterprise information and hence the way this information is utilized (Cui et al., 2007).

Business intelligence is not a single entity; it is decomposed into business information. Crosspollination of the value drivers identifies three major components to business intelligence within a business enterprise:

(1) Relationship intelligence. Understanding of how the interactions between knowledge workers influence the organizational performance.
(2) Competence intelligence. Understanding of how the abilities/proficiency of knowledge workers influences organizational performance.

(3) Structure intelligence. Understanding of how an organization's infrastructure environment influences organizational performance (Green, 2007).

Wixom and Watson (2010) define BI as: "a broad category of technologies, applications, and processes for gathering, storing, accessing, and analyzing data to help its users to make better decisions." (p. 14). Turban, et al. (2002: 460) define $\mathrm{BI}$ as a computer-based decision analysis usually done online by managers and staff. It includes forecasting, analysing alternatives and evaluating risk and performance.

$\mathrm{BI}$ is a systematic process, by which knowledge needed for an organisation to compete effectively, is created, captured, shared and leveraged (Foo et al., 2007). Davenport (2006) defines BI as a term which: "encompasses a wide array of processes and software to collect, analyze, and disseminate data, all in the interest of better decision-making." (pp. 106-107).

The key to BI is to capture and share such knowledge. BI is often confused with IT systems and processes. Unlike information, knowledge resides in the experiences of people in different contexts. The aim of BI in an organisation is to work within business processes that create, and transfer knowledge throughout the organisation. If knowledge is created and transferred via human experiences then these business processes must encompass an understanding of how people learn 
and transfer their knowledge (Sharma and Djiaw, 2011).

\subsection{Knowledge management definition}

Knowledge management refers to a systematic and organizational specific framework to capture, acquire, organize, and communicate both tacit and explicit knowledge of employees so that other employees may utilize them to be more effective and productive in their work and maximize the organization's knowledge (Davenport et al., 1998).

Knowledge Management (KM) is not always about technology, but also about understanding how the people work, brainstorming, identify groups of people who work together and how they can share and learn from each other and in the end the organization learning about their workers experience and about the leadership the organization. (Muhammad et al., 2014).

Based on actual experiences of the leading global KM case studies, the components for KM can be broadly categorized into three classes - People, Processes, and Technology (Figure 2). While all three are critical to build a learning organisation and get business results from KM, a majority of organisations worldwide implementing KM have found it relatively easier to put technology and processes in place, whereas the "people" component has posed greater challenges (Bhojaraju, 2005).

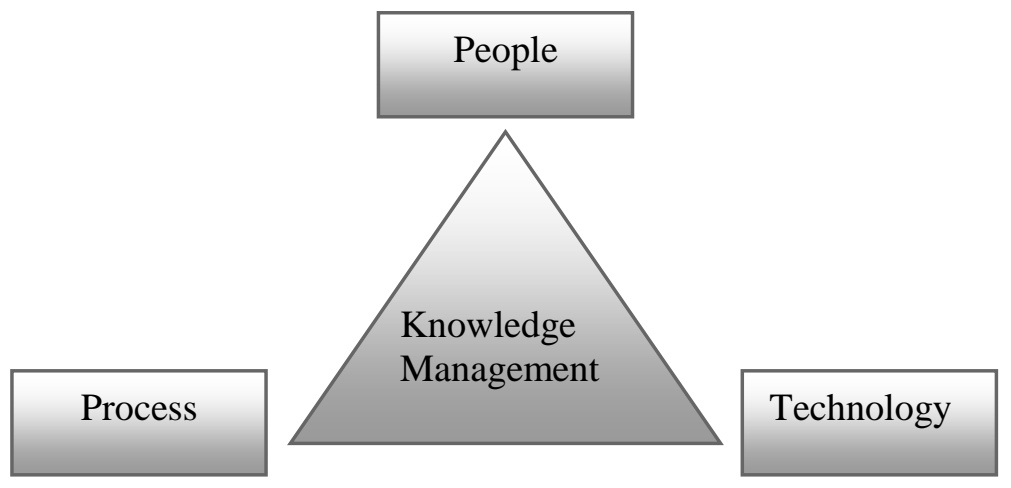

Figure 2: Components of Knowledge Management

When analysing these dimensions, it appears clear that knowledge management in an organization is facilitated by the coordination among the three important elements:

- People - who create individual and collective knowledge by learning, knowledge sharing, problem solving, integrating knowledge with corporate culture, in order to finally launch better and better products and services.

- Processes - which should be regularly updated with currently available information and knowledge, and improved adequately.

- Technologies, and in particular information technologies - which should be developed in line with market demands, in reply to competitors' activities and based on a company's resources. (Olszak and Ziemba,2010).

$\mathrm{KM}$ is a process of knowledge creation, validation, presentation, distribution, and application (Bhatt,2001). KM is achieving organizational goals through the strategy-driven motivation and facilitation of knowledge workers to develop, enhance and use their capability to interpret data and information (by using available sources of information, experience, skills, culture, character, personality, feelings, etc.) through a process of giving meaning to these data and information (Beijerse, 1999).

\subsection{The Similarities and Differences between BI and KM}

Enterprises have been investing in technology in an effort to manage the information glut and glean knowledge that can be leveraged for a competitive edge. Two technologies in particular have shown good return on investment in some application of research and development. The technologies are business intelligence and knowledge management (Cody et al, 2002).

Knowledge management and business intelligence systems have been around for a long time. KM systems are people centric. People create, share, disseminate, use and apply knowledge. Although BI includes various tools and technologies, the most decisions and actions are taken and implemented by people. Although people play crucial role in both the systems, the distinguishing fact is: in KM systems people use knowledge from various knowledge sources and apply them to address the problems 


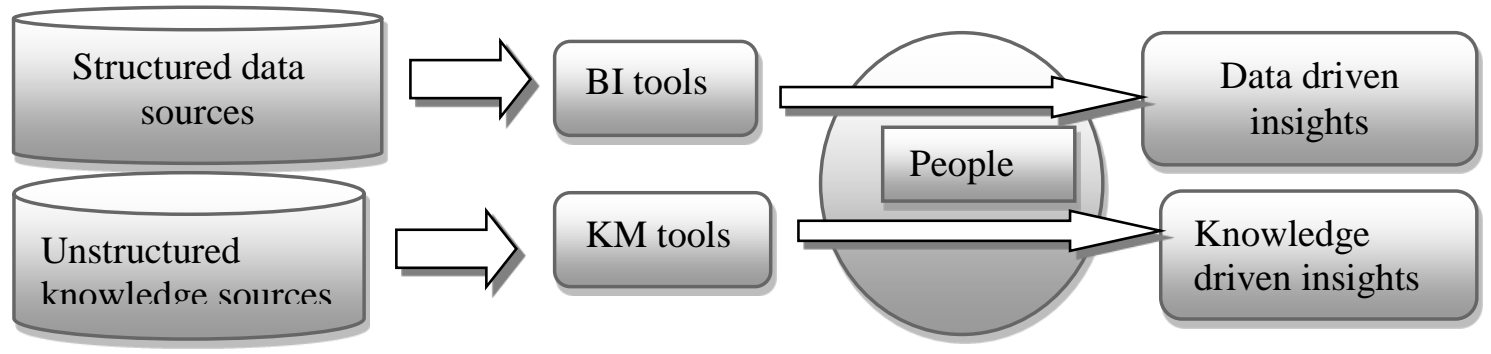

Figure 3 : People centric BI and KM

Business Intelligence (BI) and Knowledge Management (KM) are the main tools to achieve the organizational tool by providing the environment which users receive, desire and find reliable as timely information or knowledge. The organizations need both BI and Knowledge Management (KM) as an integrated system to get value from explicit and implicit knowledge (Khan \& Quadri, 2012).

BI exploits the advantage of huge repositories of data present with and outside the organization. It extracts valuable information/knowledge from various sources of data (Khan \& Quadri, 2012). Similar to BI, KM improves the use of information and knowledge available to the organization (Sun and Chen, 2008). However, KM is distinct from BI in many aspects. According to a survey by OTR consultancy, 60 percent of consultants did not understand the difference between the two. (Herschel and Jones, 2005). Main differences between BI and KM have been well described in the table 1 .

Table 1. Difference between BI and KM (Rao and Kumar, 2011).

\begin{tabular}{|c|c|c|}
\hline & BI & $\mathbf{K M}$ \\
\hline Sources & $\begin{array}{l}\text { Internal and external structured data } \\
\text { sources. Data about suppliers, employees } \\
\text { and customers etc. }\end{array}$ & $\begin{array}{l}\text { Expert employees, Communities of } \\
\text { interests / practices, organization, Market } \\
\& \text { Competitors structured/ unstructured } \\
\text { data sources. }\end{array}$ \\
\hline IT & $\begin{array}{l}\text { Source systems, ETL ,DW,OLAP, Meta } \\
\text { Data, Data Mining ,Statistical Analysis } \\
\text { reporting and user interface }\end{array}$ & $\begin{array}{l}\text { Document management, Web content } \\
\text { management, enterprise knowledge portal, } \\
\text { work flow, collaboration and e-learning }\end{array}$ \\
\hline $\begin{array}{l}\text { Business } \\
\text { Process }\end{array}$ & $\begin{array}{l}\text { Converts data into information \& then into } \\
\text { knowledge that finally meets needs of end- } \\
\text { user. }\end{array}$ & $\begin{array}{l}\text { Knowledge } \begin{array}{c}\text { Sharing, } \\
\text { extraction, Knowledge } \\
\text { Knowledge }\end{array} \\
\text { application, and knowledge innovation. }\end{array}$ \\
\hline Deals with & $\begin{array}{l}\text { Explicit Knowledge, which is extracted } \\
\text { from operational data. KPI, Process } \\
\text { optimization, predict from internal and } \\
\text { external data. }\end{array}$ & $\begin{array}{l}\text { It deals with explicit as well as tacit } \\
\text { knowledge. Informal, Formal, synergic and } \\
\text { operational knowledge. }\end{array}$ \\
\hline Objective & $\begin{array}{l}\text { Identifies trends and patterns in structured } \\
\text { data for developing new business strategies. } \\
\text { Utilizes the massive data to discover the } \\
\text { knowledge to provide competitive } \\
\text { advantage. }\end{array}$ & $\begin{array}{l}\text { Captures, stores, organizes, and distributes } \\
\text { organizational knowledge and resources. It } \\
\text { deals with the unstructured knowledge and } \\
\text { tacit } \\
\text { knowledge of the employees. }\end{array}$ \\
\hline Depends & $\begin{array}{l}\text { It depends on } \mathrm{KM} \text { to receive } \\
\text { feedback/experience from end-users and } \\
\text { then to modify the solution, if required. }\end{array}$ & $\begin{array}{l}\text { Depends on BI techniques to implement in } \\
\text { an efficient way and explicit knowledge } \\
\text { generated by BI. }\end{array}$ \\
\hline
\end{tabular}




\section{BI and KM benefits for the organization}

\subsection{Benefits of BI}

In the last decade, BI has evolved as one of the critical applications in organizations to provide useful insight, support decision-making, and drive organizational performance (On, 2006). There are, of course, many other definitions of the benefits of business intelligence. Carver and Ritacco (2006, p. $6)$, for instance, divide them into four groups: (1) lowering costs; (2) increasing revenue; (3) improving customer satisfaction; and (4) improving communication within the company. Similarly, Atre \& Moss (2003, p. 39) categorize the benefits of business intelligence as: (1) an increase in revenue; (2) an increase in profit; (3) improved customer satisfaction; (4) a reduction of costs; and (5) an increase in market share.

In the survey, KPMG identify several expected BI outcomes. They are:

- better decision making;

- better customer handling;

- faster response to key business issues;

- $\quad$ improved employee skills;

- $\quad$ improved productivity;

- $\quad$ increased profits;

- $\quad$ sharing best practices;

- reduced costs;

- $\quad$ increased market share;

- creation of new business opportunities; and

- $\quad$ improved new product development.

\subsection{Benefits of KM}

KM can help organizations to provide better service, enhance quality product, reduce cost and respond faster to their customers (McAdam and McCreedy, 2000). Efficient knowledge management has a positive effect on organisational performance (Drucker, 1994). The knowledge management process aims to support innovation and encourage the free flow of ideas through the company. It helps increasing revenues and reducing costs. The knowledge management process increases the value of the company and its competitiveness as a whole, because it increases the efficiency and effectiveness, the relationship of all resources and innovation (Tisen et al., 2006, p. 47). The importance of knowledge management and its link with business performance have been recognised: companies need to spend relevant management efforts towards this direction (Canzano and Grimaldi, 2012).
The benefits of using KM in the organizations are:

- Helps drive strategy

- Solves problems quickly

- Diffuses best practices

- Improves knowledge embedded in products and services

- Cross-fertilizes ideas and increases opportunities for innovation.

- Enables organizations to stay ahead of the competition better.

- Builds organizational memory (Dalkir, 2005, p. 20).

\subsection{Integration BI and KM}

\subsection{Relationship between BI and KM}

Business intelligence plays a central role in knowledge management (White, 2005). Business intelligence is a form of knowledge. The techniques used in knowledge management for generating and transferring knowledge (ALShubiri, 2012).

$\mathrm{BI}$ is seen as an integral part of a larger $\mathrm{KM}$ effort. The effectiveness of BI integrated with KM effort will help not only to promote and enhance knowledge for better decision making, but also improve an organisation's performance. According to Wang and Wang (2008), there should be interactions between knowledge workers through BI techniques and business decision makers for knowledge sharing and improvement to happen in an organisation. The provision of quality information is the key to gaining competitive advantages. Better information leads to better strategies, tactics, and a more efficient decisionmaking process ( Schwartz and Teeni, 2011, p.73).

Herschel (2008) argued that BI activities should lead to knowledge improvement. In other words, "the effectiveness of BI should measure based on how well it promotes and enhances knowledge, how well it improves the mental model(s) and understanding of the decision maker(s), and how well it improves decision making and, hence, firm performance. Business intelligence should therefore be viewed as an integral part of KM".

Some researchers see the relationship differently. They argue that KM and its processes are helping hand of $\mathrm{BI}$ and make it more pervasive in organizations (Zarghamifard and Behboudi, 2012). Haimila (2001) also sees KM as the "helping hand of BI". He cites the use of BI by law enforcement agencies as being a way to maximize their use of collected data, enabling them to make faster and better-informed decisions because they can drill down into data to see trends, 
statistics and match characteristics of related crimes (Herschel and Jones, 2005). Harold M. Campbell created a business intelligence model through knowledge management in his paper "The role of organizational knowledge management strategies in the quest for business intelligence." There are three strategic value propositions which are included in the above model which the organization may use. These are:

1) The need to manage their staff member as assets, who add meaning to information;

2) The need to set up structures that allow staff members to gather and distribute information, but most importantly to convert that information into bottom-line income;

3) The need to be in touch with, and responsive to, the needs of the customers of the organizations; they are the best, and final, arbiters of an organizations' actions. These value propositions are encapsulated in a model for creating BI through KM (Shrivastava and Lanjewar, 2012).

It can be argued that there exists an interaction effect between KM activities and BI efforts. For example, as Malhotra notes, artificial intelligence and expert systems are intended to help deliver the "right information to the right people at the right time." But, this can only happen if the right information and the right person to use or apply it, and the right circumstance and appropriate time are known in advance. Detection of non-routine and unstructured change depends on the sense-making capabilities of knowledge workers for correcting and validating the computational logic of the business and the data it processes. Further complicating this issue is the realization that the same assemblage of data may evoke different responses from different people at different times or in different contexts ( Herschel and Jones, 2005).

\section{$5.2 \mathrm{BI} / \mathrm{KM}$ or $\mathrm{KM} / \mathrm{BI}$ ?}

Integrated BI and KM provide a robust system with the capability of process-driven decision making. The processes are stored in process model base and their flexibility and reuse help enterprises improve the speed and effectiveness of business operations (Lee, 2000). BI and KM must be integrated in order to promote organisational learning and effective decision making (Cook \& Cook, 2000). Campbell discussed KM, components of KM, BI and Integration of BI and KM.

There have been several models of integration of $\mathrm{BI}$ and $\mathrm{KM}$ reported in the literature. At the conceptual level, Malhotra (2004) has proposed general models of integration of $\mathrm{KM}$ and $\mathrm{BI}$ for routine structured information processing and nonroutine unstructured sense making. White (2005) provides a flowchart model that articulates the use of $\mathrm{BI}$ in the KM context for decision making. The flowchart model illustrates the involvement of collaboration and interaction between the knowledge workers for socialization. (Wang and Wang, 2008).

Adirekpullap (2008) evaluated a framework of business intelligence systems and then explore the development integration framework of the BI and $\mathrm{KM}$ process, so called BIKM framework. You (2010) discusses how KM and data mining can become more valuable for real time BI. Also, KM tools can provide a repository for organizing these reports among other relevant information and for collaborative business intelligence (CBI) (Stavrianos and Henderson, 2006). KM practices make BI more pervasive throughout the organization (Vesset and McDonough, 2009). Cheng and Peng analyze BI and KM, and explain their pros and cons followed by proposing a framework named the KMBI Framework that integrates KM and BI. The KMBI is built on three layers: data integration, function integration and presentation integration. $\mathrm{KM}$ and BI have different features and the integration of both can maximize organizational efficiency and provide the best services to the customers (Shehzad and Ahmed Khan, 2013).

\subsection{Stages in Integrating KM and BI}

Integration is an ambiguous term that has many interpretations in different domains. For example, in strategy, it means "coordination of activities and management of dependencies between them". In production and logistics, it is "coordinated management of information, material flows, plant operations and logistics through a common sets of principles, strategies, policies and performance metrics". The dictionary also provides multiple definitions for integration, for example "the act of combining or adding parts to make a unified whole". In the domain of information technology, integration is often associated with different perspectives (Kahkonen and Smolander, 2013). There are three levels of integration between BI and KM: (1) Presentation level integration provides a horizontal integration with a joint user interface. (2) Data level integration provides the content of KM systems for BI processes by storing the related metadata into data warehouse. (3) System level integration provides distribution and re-utilization of BI analysis models by a knowledge management system (Rao and Kumar,2011).

$\mathrm{KM}$ and BI a distinct but interrelated terms of common foundation, mutual effects, complementarities, and synergy ( Zarghamifard and Behboudi, 2012). Stages of Integrating KM and BI have been described in 4 steps (Figur 4). 


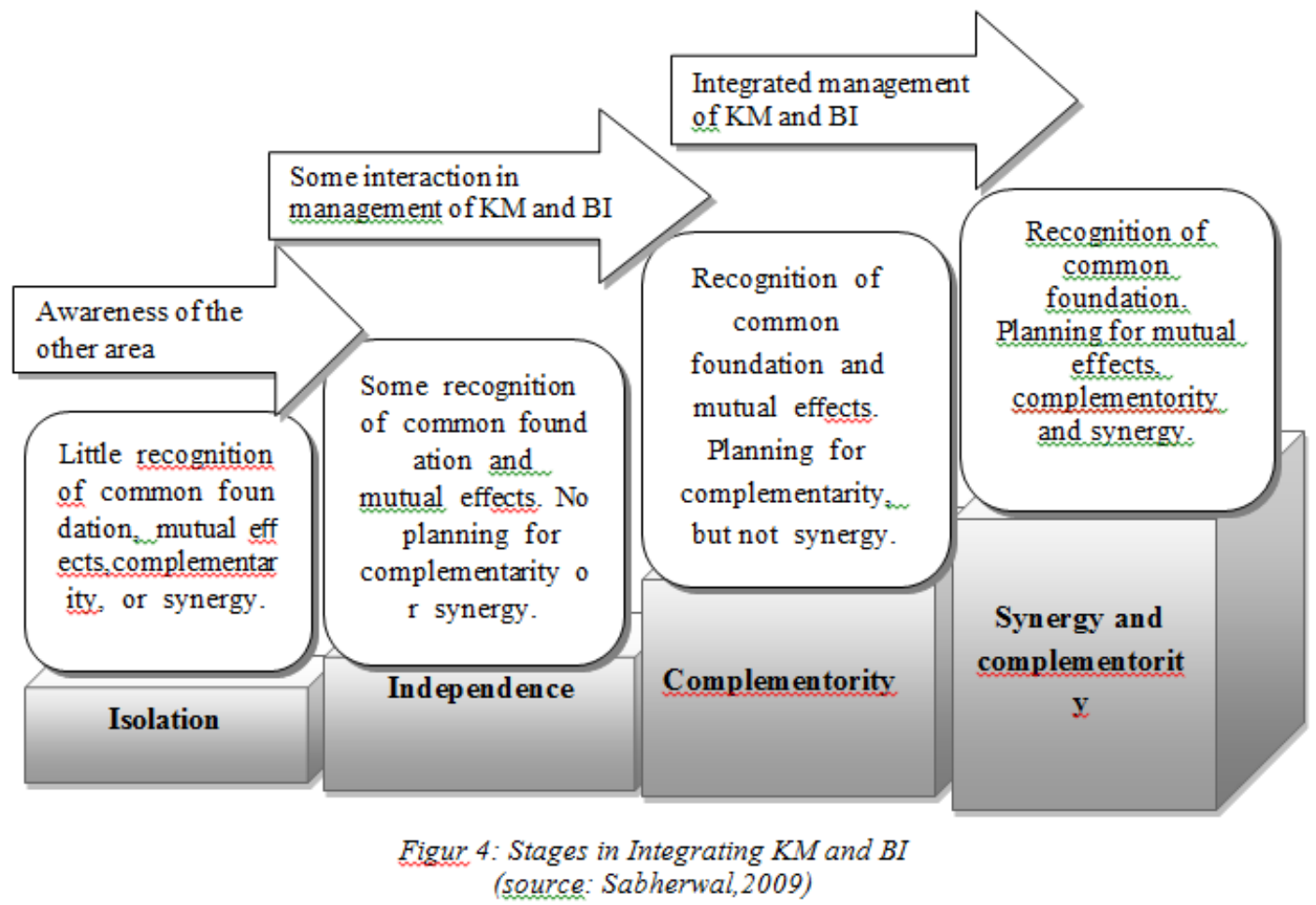

According to the American Heritage Dictionary of the English Language, synergy is defined as the interaction of two or more agents or forces so that their combined effect is greater than the sum of their individual effects or cooperative interaction among groups, especially among the acquired subsidiaries or merged parts of a corporation, that creates an enhanced combined effect (Taib et al., 2008).

As shown in the figur 4 , integrating $\mathrm{BI}$ and $\mathrm{KM}$ process generate synergy. Therefore, it is expected that the effects produced by combining the $\mathrm{KM}$ and $\mathrm{BI}$ functions will be greater than the sum of their individual effects. This synergy can be important to create and sustain competitive advantages that will lead the organizations to compete strategically in the K-Economy.

\subsection{Integration BI and KM benefits for the organization}

integrating Business Intelligence and Knowledge Management in order to respond to the challenges the modern enterprise has to deal with represents not only a "new trend" in IT, but a necessity (Albescu et al., 2008). KM and BI have different features and the integration of both can maximize organizational efficiency and provide the best services to the customers (Cheng and Cheng, 2011).
The benefits of integrating of BI with KM are to 1) Ensure a real support in deploying successful business across the organization by smoothly managing multicultural teams of employees in providing highest quality products and global services to multicultural customers, 2) end-user preference and experience can be included in BI implementation, and 3) provide better understanding on business context, interpretation results and training to the end-user (Rao and Kumar, 2011).

Integrating $\mathrm{BI}$ and $\mathrm{KM}$ provides real technological support for Strategic Management (Albescu et al., 2008). This integration will not only facilitate the capturing and coding of knowledge but also enhances the retrieval and sharing of knowledge across the organization to gain strategic advantage and also to sustain it in competitive market (Khan and Quadri, 2012). See also the topic of Integrating Knowledge Management with Business Intelligence Processes for Enhanced Organizational Learning (Shehzad and Ahmed Khan, 2013). BIKM is the new term that represents the integration and can be determined as one of the key success factors in modern business. Integration of BI and KM will provide an harmonious tool for enterprise to exploit valuable information and knowledge and gain sustainable competitive advantage (Adirekpullap, 2008). 


\section{Conclusion}

Rapid developments of techniques and technologies have driven the needs for the application of new knowledge in workplaces. In modern businesses, increasing standards, automation, and technologies have led to vast amounts of data becoming available. This explosive growth has generated an even more urgent need for techniques and tools that can assist us convert this data into useful information and knowledge which can meet customer requirements. In today's world of complex and dynamic, more knowledge-based companies than ever are in need of having knowledge management and Business intelligence.

In this article we discussed BI and $\mathrm{KM}$ benefits. Business Intelligence can bring critical capabilities to an organization. business intelligence systems to allow organizations to access, analyze, and share information and knowledge. Also, KM improves the use of information and knowledge available to the organization. Therefore, it can conveniently be assumed that BI and KM play an important role in improving the qualitative and quantitative value of information available for decision making. As we discussed, KM and BI can benefit from each other. Business intelligence has an important role to play in knowledge management projects. Business intelligence techniques are used in knowledge management for generating and transferring knowledge. There exists an interaction effect between KM activities and BI efforts, which is discussed in greater detail in other articles.

We can conclude that proper integration of BI \& KM can help organization to get wide benefits. It includes maximize organizational efficiency, Enhanced Organizational Learning and improvement organization performance. We have also discussed the Stages in Integrating KM and BI.

Both KM and BI are deeply influenced by the culture of the organization, especially leadership, groups and opinion leaders, as well as organizational. With successful integration between knowledge management and business intelligence, every company can ensure its viability and outpace its competitors. If an organization aims to develop competitive advantage from information that it has collected then it is best to implement an integrated BI and KM strategy. However, the success of each firm depends largely on its human factor. Since culture is a KM critical success factor and is largely expressed through tacit behavior, we can examine issues that culture can have on BI and KM integration efforts.

Although using integration of BI and KM has many benefits and advantages for organizations, studies show that business intelligence projects without due attention to necessary conditions presented here is inefficient. If factors affecting integration of $\mathrm{BI}$ and $\mathrm{KM}$ of business are identified and understood, better integration strategies can be designed.

\section{References}

Adirekpullap. T. (2008). "Integration of business intelligence and knowledge management as a strategic intelligence tool", University of Nottingham, a management project presented in part consideration for the degree of general MBA.

Ahmad Khan, R. and Quadri, S.M. K. (2012). "business intelligence: an integrated approach", Business Intelligence Journal - January, 2012 Vol.5 No.1, p.64-70.

AL-Shubiri F. (2012). "Measuring the impact of business intelligence on performance: an empirical study “,polish journal of management studies, vol.6, p.162-173.

Albescu, F., Pugna, I. and Paraschiv, D. (2008). "Business Intelligence \& Knowledge Management - technological support for strategic management in the knowledge based economy", Revista Informatica Economică, Nr. 4(48).

Atre, S. and Moss, L. T. (2003). "Business Intelligence Roadmap". The Complete Project Lifecycle for Decision-Support Applications. Boston: Addison-Wesley.

Bhatt, G.D. (2001). "Knowledge Management in organizations: examining the interaction between technologies, techniques and people". Journal of Knowledge Management 5(1),68-75.

Beijerse, R.P.U. (1999). "Questions in Knowledge Management: defining and conceptualizing a phenomenon". Journal of Knowledge Management, 3(2), 94-109.

Boonsiritomachai, W., McGrath, M. and Burgess, S. (2014). "A research framework for the adoption of Business Intelligence by Small and Medium-sized enterprises", Small Enterprise Association of Australia and New Zealand 27th Annual Seaanz Conference.

Bhojaraju, G. (2005). "knowledge management: why do we need it for corporates", Malaysian Journal of Library \& Information Science, Vol. 10, no.2: 37-50.

Campbell, H. M. (2010), "The liberation of Intellectual Capital through the natural evolution of Knowledge Management Systems", IEEE.

Canzano, D. and Grimaldi, M. (2012). "An integrated framework to implement a knowledge management programme: the role of technological tools and techniques", Int. J. Intelligent Enterprise, Vol. 1, Nos. 3/4, P. 233347. 
Carver, A. \& Ritacco, M. (2006). The Business Value of Business Intelligence. A Framework for Measuring the Benefits of Business Intelligence. Business Objects.

Cheng, L. and Cheng, P. (2011). "Integration Knowledge Management and Business Intelligence", IEEE.

Cook, C., \& Cook, M. (2000). The Convergence of Knowledge Management and Business Intelligence. New York: Auerbach Publications.

Cody, W.F., kreulen, J.T., Krishna, V. \& Spangler W.S. (2002). "the integration of business intelligence and knowledge management", IBM system journal, VOL. 41, NO. 4, P. 697-713.

Dalkir, K. (2005). "Knowledge Management in Theory and Practice", Burlington: Elsevier Butterworth-Heinemann.

Davenport, T. H., \& Prusak, L. (1998). Working knowledge: How organisations manage what they know. Boston: Harvard Business Press.

Davenport, T.H. (2006). Competing on Analytics. Harvard Business Review, 84(1): 98-107.

Drucker, P.F. (1994). "The age of social transformation", The Atlantic Monthly, 274(5), 53-80.

Cui, Z., Damiani, E. and Leida, M. (2007). "Benefits of Ontologies in Real Time Data Access", Digital EcoSystems and Technologies Conference, DEST '07. Inaugural IEEE-IES, , pp. 392-397, 21-23.

Green, A. (2007). "Business information - a natural path to business intelligence: knowing what to capture", The journal of information and knowledge management systems Vol. 37 No. 1, pp. 18-23.

Herschel, R., (2008). Knowledge Management and Business Intelligence, available. at: http://www.b-eye-network.com/view/7621.

Herschel, R.T. and Jones N.E. (2005). "Knowledge management and business intelligence: the importance of integration", journal of knowledge management, VO L. 9 N O. 42005 , pp. 45-55,

Jaklic, J., Coelho. P.S and Popovic, A. (2009). "Information Quality Improvement as a Measure of Business Intelligence System Benefits", wseas transactions on business and economics, Issue 9, Volume 6,

Kahkonen T., Smolander K. (2013). "ERP Integration - A Systematic Mapping Study", in International Conference on Enterprise Information Systems, Angers, France.

Khan, R. A., \& Quadri, S. K. (2012). Dovetailing of Business Intelligence and Knowledge Management: An Integrative Framework. Information and Knowledge Management. Vol 2, No.4.

Kimpel, J.F and Morris, R. (2013). "Critical success factors for data warehousing: a classic answer to a modern question", Issues in
Information Systems, Volume 14, Issue 1, pp.376-384.

KPMG International (2000). Knowledge Management Research Report 2000 , KPMG Consulting,London, available at: www.providersedge.com.

Lee, J. S. (2000). Knowledge Management: The Intellectual Revolution. IIE Solutions, 32, 3437.

McAdam, R. and McCreedy, S. (2000). A critique of knowledge management using a social constructionist model, New Technology, Work and Employment, Vol. 15, No. 2, PP. 155-168.

Muhammad, G., Ibrahim, J., Bhatti, B., and Waqas, A. (2014). "Business Intelligence as a Knowledge Management Tool in Providing Financial Consultancy Services", American Journal of Information Systems, Vol. 2, No. 2, 26-32.

Negash, S. (2004). "business intelligence", Communications of the Association for Information Systems, Volume13, 177-195 .

Olszak, C.M. and Ziemba, E. (2010). "Knowledge Management Curriculum Development: Linking with Real Business Needs", Issues in Informing Science and Information Technology, Volume 7, P.235-248.

On, P. (2006). "The Importance of Enterprise Information Management for Business Intelligence," Business Intelligence Journal 11:1, pp. 49-54.

Panian, Z. (2008). "How to Make Business Intelligence Actionable through Serviceoriented Architectures", WSEAS Transactions on Business and Economics, Vol.5, No.5, pp. 210-221.

Rao, G.K. and Kumar, R. (2011). "framework to integrate business intelligence and knowledge management in banking industry", Review of Business and Technology Research Vol. 4, No. 1.

Ranjan, J. (2008). "Business justification with business intelligence", The journal of information and knowledge management systems Vol. 38 No. 4, pp. 461-475.

Sabherwal, R. (2009). "Knowledge Management and Business Intelligence: Resource Competitors or Synergistic Forces?", https://business.queensu.ca/centres/monieson/F ulbrightPresentation-Oct5-2009.pdf

Schwartz, D.G. and Te'eni, D. (2011). "Encyclopedia of knowledge management", Second Edition ,United States of America, Information Science Reference.

Sharma, R.S. and Djiaw, V. (2011). "Realising the strategic impact of business intelligence tools", The journal of information and knowledge management systems, Vol. 41 No. 2, pp. 113131. 
Shehzad, R. and Ahmed Khan, M.N. (2013). "Integrating Knowledge Management with Business Intelligence Processes for Enhanced Organizational Learning”, International Journal of Software Engineering and Its Applications , Vol. 7, No. 2, P.83-92.

Shrivastava, A. and Lanjewar,U. (2012). "Research Agenda: Behavioural Business Intelligence Framework for Decision Support in Online Retailing in Indian Context", International Journal of Scientific and Research Publications, Volume 2, Issue 5.

Sonar, R.M. (2011). "People centric BI and KM: Relationship and Integration", www.csi-india.org.

Taib, K.M., Yatin, S.F.M., Ahmad, A.R. and Mansor, A.N. (2008). "Knowledge Management and Competitive Intelligence: A Synergy for Organizational Competitiveness in the K-Economy", Communications of the IBIMA, Volume 6, P.25-34.

Tisen, R., Andriessen, D. \& Lekan Deprez, F. (2006). The Knowledge Dividend: Creating high-performance companies through valuebased knowledge management. Financial Times Prentice Hall.

Turban, E., McLean, E., Wetherbe, J., Bolloju, N. and Davison, R. (2002). Management technology for management: transforming businesses in the digital economy. New York: John Wiley.

Vesset, D. and McDonough, B. (2009). Taking lessons from $\mathrm{KM}$ to influence business intelligence pervasiveness. KM World, Vol. 18 (4), pg. 20-23.

Vine, D. (2000). Internet Business Intelligence: How to Build a Big Company System on a Small Company Budget , Cyberage Books, Medford, NJ.

White, C., (2005). The Role of Business Intelligence in Knowledge Management, available at : http://www.b-eyenetwork.com/view/720 accessed 15/11/2010.

Williams, S., \& Williams, N. (2007). The Profit Impact of Business Intelligence: Morgan Kaufmann.

Wixom, B. and Watson, H. (2010). The BI-Based Organization. International Journal of Business Intelligence Research, 1(1): 12-24

You, H. (2010). "A Knowledge Management Approach for Real-time Business Intelligence", IEEE.

Zarghamifard, M. and Behboudi, M. R. (2012). "Exploring the Underlying Relations between the Business Intelligence and Knowledge Management", International Journal of Science and Engineering Investigations, vol. 1, issue 2, P.31-35. 